\title{
O ensino de Português como Língua de Acolhimento (PLAC) na linha do tempo dos estudos sobre o Português Língua Estrangeira (PLE) no Brasil
}

\author{
Flávia Campos Silva \\ Centro Federal de Educação Tecnológica de Minas Gerais \\ (CEFET-MG) \\ flaviariff@yahoo.com.br \\ Eric Júnior Costa \\ Centro Federal de Educação Tecnológica de Minas Gerais \\ (CEFET-MG) \\ linguistica13@gmail.com
}

\section{Resumo}

Com este trabalho tem-se a pretensão de situar e caracterizar o ensino de Português como Língua de Acolhimento (PLAc) na linha do tempo dos estudos sobre o Português Língua Estrangeira (PLE). A proposta é contextualizar o ensino do PLE no Brasil, com ênfase nas políticas linguísticas que envolveram - e ainda envolvem - esse tipo de aquisição de Português (ALMEIDA FILHO, 1999, 2005, 2012; CUNHA; SANTOS, 2002). Na sequência, com o amparo de teorizações de Grosso (2010), Amado (2011), Arantes et. al (2016), Cursino et. al (2016), Lopez (2018) e Diniz e Neves (2018), serão situadas e caracterizadas as concepções de PLAc, com ênfase nas suas especificidades, motivadas por questões geopolíticas e pelo multilinguismo global, especialmente. A conclusão indica que o PLAc representa uma perspectiva outra, inovadora e significativa no campo do PLE, uma vez que, além de assistir a demandas não atendidas pelo Estado (COSTA; SILVA, 2018), baseia sua metodologia numa cultura de ensino participada, que respeita os processos de (re)construção identitária dos sujeitos (ANUNCIAÇÃO, 2018) com foco na promoção da cidadania e na consciência e diálogo interculturais.

Palavras-chave: PLE. PLAc. Políticas Linguísticas. Migração e Ensino de Línguas.

\section{Abstract}

This work has the pretension to situate the teaching of Portuguese as Host Language (PHL) in the timeline of studies about the Portuguese Foreign Language (PFL). The proposal is to contextualize the teaching of the PFL in Brazil with emphasis on the 
linguistics policies that involved -and still involves - this type of acquisition of Portuguese (ALMEIDA FILHO, 1999, 2005, 2012; CUNHA; SANTOS, 2002). Following, supported by the theorizations of Grosso (2010), Amado (2011), Arantes et. al (2016), Cursino et. al (2016), Lopez (2018), Diniz and Neves (2018) the conceptions of PHL will be situated and characterized, emphasizing the specificities motivated by geopolitics and global multilingualism, especially. The conclusion is that the PHL represents a another perspective, innovative and significant in the field of PLE, since, in addition to attend unmet demands by the State (COSTA; SILVA, 2018) bases its methodology on a culture of shared teaching, which respects the processes of identity re-construction of the subjects (ANUNCIAÇÃO, 2018), with a focus on promoting citizenship and in consciousness and intercultural dialogue.

Keywords: PFL. PHL. Language Policies. Migration and Language Teaching.

\section{Introdução}

A partir do século 21, o ensino de Português Língua Estrangeira (PLE) passou a ocupar outros espaços, ampliando o seu escopo principalmente no contexto transnacional (ZOPPI-FONTANA, 2009; BAENINGER; PERES, 2017). Referimo-nos aos novos contornos que os fluxos migratórios e seus agenciamentos foram ganhando e às necessidades de comunicação e intercâmbio linguístico-cultural que se impuseram à Língua Portuguesa a partir de então. Diante desse quadro, pode-se dizer que o Português assumiu um caráter mais pluricêntrico (OLIVEIRA, 2015) e atuante em um cenário (re)configurado e (res)significado pela ampliação, principalmente, do público.

Essa realidade, em que a área de PLE está inserida, tem demandado muitas reflexões a respeito dos caminhos que os estudos da Linguística Aplicada vêm tomando no Brasil no campo do ensino de línguas. Diante de demandas inéditas e da urgência em assisti-las frente a omissões governamentais (COSTA; SILVA, 2018), uma nova situação socioeducativa emerge em atendimento à necessidade de aprendizagem da língua majoritária do nosso país por parte de migrantes ${ }^{1}$ em situação de vulnerabilidade. Referimo-nos ao Português como Língua de Acolhimento (PLAc), uma iniciativa que, por meio do ensino de Português a partir do fomento da

\footnotetext{
${ }^{1}$ Optamos pelo termo "migrante" para este artigo, porque tomamos como referência o sujeito que se desloca e não os países de origem e destino, para os quais ele seria emigrante ou imigrante.
} 
acolhida solidária, tem participado ativamente do agenciamento de questões (extra)linguísticas do sujeito migrante no nosso país.

Posicionado como uma abordagem de ensino referenciada/reconhecida no Brasil há aproximadamente dez anos, o PLAc caracteriza-se como uma prática orientada para a ação em que "ensinante e aprendente cooperam e aprendem juntos (...) e integram-se pelo bem-estar e pela confiança" (GROSSO, 2010, p. 71), por meio de uma cultura de ensino que privilegia a participação e que "propõe a abrir-se à compreensão do outro.” (p. 74). Trata-se de uma prática que considera as questões psicossociais e discriminatórias pelas quais sofrem os aprendizes e que abrange competências comunicativas em diferentes níveis.

Com os primeiros trabalhos datados a partir de 2010/2011 (GROSSO, 2010; AMADO, 2011)), o PLAc adota uma práxis que visa a conscientizar o aprendiz de que a língua não apenas está posicionada como um instrumento necessário à vida em sociedade, mas também, e principalmente, representa uma potencial ferramenta de emancipação. Ela seria capaz de impulsionar a ocupação de outros loci de enunciação no novo endereço de domicílio e, consequentemente, movimentar padrões de sociabilidade por meio das inteligibilidades emergentes no processo de aprendizagem.

Diante desse quadro, é possível observar uma (res)significação do cenário socioespacial. Devido às movimentações geopolíticas marcadas pelos intensos fluxos migratórios - que não existem sem consequências para os sujeitos envolvidos (MORO, 2015) -, o ensino de Português participa do processo de (re)territorialização (DELEUZE; GUATTARI, 2004) do migrante. O objetivo seria impedir que a língua represente um "risco de exílio" (REVUZ, 1998) e dificulte ainda mais a tão desejada e necessária integração na sociedade que o acolheu.

Nossa proposta é: contextualizar o ensino de PLE com ênfase nas políticas linguísticas que envolveram - e ainda envolvem - esse tipo de aquisição de Português, a partir dos pressupostos de Almeida Filho (1999, 2012) e Cunha e Santos (2002) e, amparados pelas teorizações de Grosso (2010), Amado (2011), Arantes et. al (2016), Cursino et. al (2016), Lopez (2018) e Diniz e Neves (2018); além de situar e caracterizar o PLAc e suas especificidades. Acreditamos que essa práxis pedagógica - ainda em construção - tem apontado para aspectos inexplorados do agenciamento linguístico frente aos fluxos migratórios no Brasil e indicado caminhos de gestão possíveis quanto às movimentações que vêm ocorrendo nos espaços 
hegemônicos e nos comportamentos sociais (SANTOS, 2001) das sociedades de trânsito e/ou de destino de migrantes, principalmente, migrantes de crise (CLOCHARD, 2007), isto é, migrantes que deixaram seus países à força, em razão de sobrevivência.

Por meio de um breve e crítico resgate histórico, pretendemos atualizar o quadro metodológico dessa empreitada socioeducativa do ponto de vista do ensino de línguas, sendo impulsionados por reflexões teóricofilosóficas que consideramos como fundamentais tanto para a compreensão do contexto em que esta abordagem de ensino está inserida, quanto para a compreensão da prática propriamente dita, cada vez mais notória e relevante nos estudos de PLE no Brasil.

\section{Português Língua Estrangeira (PLE)}

O ensino de Língua Portuguesa para falantes de outras nacionalidades é uma prática que se refere às políticas linguísticas no Brasil, desde o período colonial (antes mesmo de essas serem cunhadas como tal), haja vista o processo dito "civilizatório" dos povos indígenas que ocorreu no período posterior à invasão portuguesa na terra brasilis.

Inicialmente, o que temos registrado sobre o ensino de Português na história do nosso país, diz respeito às práticas nos colégios de ensino regular, a saber: o Colégio de Salvador (1550), o Colégio dos Meninos de Jesus de São Vicente (1553) e o Colégio de São Paulo de Piratininga $(1554)^{2}$ - lugar onde os indígenas foram obrigados a aprender a ler, escrever e falar o Português (ALMEIDA FILHO, 2012) para que as práticas colonizadoras fosses viabilizadas e o status quo fosse garantido pela soberania da Igreja e do Estado.

Importante pontuar que, apesar de a obrigatoriedade da escolarização poder ser considerada como um ganho quando avaliada do ponto de vista do acesso à educação e a produção e circulação de formas de conhecimento, o modus operandi da didática assimilacionista adotada na época contribuiu

${ }^{2}$ Cronologia completa em Helb: História do Ensino de Línguas no Brasil. Disponível em:

<http://www.helb.org.br/index.php?option=com_content\&view=article\&id=106:as -primeiras-faculdades-de-letras-no-brasil\&catid=1080>. Acesso em 27 de fev 2019. 
para que formas de expressão e presença no/para o mundo dos indígenas fosse violentamente adequado à dinâmica da vida colonial.

Durante os séculos 16 e 17, a Companhia de Jesus dedicou-se à elaboração do primeiro curso de Letras do Brasil, com um planejamento voltado especialmente à Filosofia e às Ciências Sagradas, bem como a publicação de dicionários e gramáticas nas línguas locais (Tupi, Kiriri) para contribuir no processo de adequação dos povos originários à dinâmica social vigente.

Podemos dizer que o marco inicial das políticas linguísticas oficiais no Brasil ${ }^{3}$ data de 1757, com o surgimento da Lei do Diretório - uma das constituições legislativas mais fortes do período colonial no que se refere à questão do ensino de Língua Portuguesa. Esse marco, resultado da atuação do Marquês de Pombal frente à expulsão dos jesuítas do território recém conquistado (TROUCHE, 2001), enfraquece o poder da Igreja e institui o Português como língua oficial da colônia de Portugal. E foi proibindo o uso de quaisquer línguas dos povos indígenas que o diplomata e estadista português não apenas reafirmou a supremacia europeia por meio de práticas heteronômicas e proibicionistas, como também fortaleceu o discurso de que o Brasil é um país monolíngue - discurso esse que perdura quase quatro séculos depois.

Durante os séculos 18 e 19, o ensino de línguas no Brasil ampliouse com a implementação do Latim e do Francês nos currículos escolares. Já em meados do século 20, à medida que a industrialização no Brasil foi se intensificando e novas demandas decorrentes especialmente da mão de obra foram surgindo, o cenário do PLE começou a ser configurado. Os estudos e a atuação profissional/científica ganharam força e o ensino de Português como língua estrangeira foi evidenciado pelo desenvolvimento econômico, cultural e pela aceleração da vida urbana. Na mesma época, o boom da Música Popular Brasileira (MPB) - com Carmem Miranda nos Estados Unidos - e o sucesso alcançado pelas primeiras grandes produções audiovisuais - representadas pelas telenovelas da extinta TV Tupi e pelos filmes do Cinema Vera Cruz (com destaque para o premiado "O Cangaceiro", Melhor Filme de Aventura em Cannes em 1953) - ajudaram a projetar o Brasil para o mundo, o que atraiu olhares de muitos estrangeiros para o nosso país.

\footnotetext{
${ }^{3}$ Não como conceito, posto que esse surge apenas na década de 1960 (CALVET, 2007).
} 
Nesse contexto, são iniciadas as primeiras pesquisas sobre PLE no Brasil, sendo o Rio Grande do Sul o estado pioneiro na publicação dos primeiros materiais de ensino com a temática. Segundo Almeida Filho (2012):

\begin{abstract}
Marcas significativas do surgimento de uma nova especialidade no Ensino de Línguas no Brasil começam a aparecer na abertura de cursos para alunos estrangeiros no sul do Brasil, como o curso de PLE da Universidade Católica do Rio Grande do Sul, para o qual a professora Mercedes Marchand criou um manual didático O ensino de português para estrangeiros em 1957, tendo sido publicado pela Editora Sulina do Rio Grande do Sul. (p. 726)
\end{abstract}

A partir de então, o ensino de PLE foi ganhando cada vez mais projeção, visibilidade e subsídios para desenvolver suas pesquisas. Segundo Almeida Filho (2005), na década de 1970, Biazioli e Gomes de Matos, do Centro Yázigy de Linguística Aplicada em São Paulo, publicaram uma série de livros sobre o ensino do PLE de forte base estruturalista, marcada por incisiva sistematização de gramática e tradução, pautada em uma metodologia áudio-lingual.

Nos anos de 1980, com o ápice dos cursos de pós-graduação, bem como o aumento do capital humano estrangeiro no Brasil, principalmente para a indústria, o PLE é posicionado em um lugar mais institucionalizado. É durante esse período, inclusive, que surgem algumas publicações mais relevantes da área e que se constituem em referência até os dias atuais: "Fala Brasil" (COUNDRY; FONTÃO, 1989); "Tudo bem" (RAMALHETE, 1984) e "Avenida Brasil" (LIMA et. al. 1992) são alguns exemplos (op cit). Juntamente com essas publicações, dissertações e teses foram defendidas e, assim como ocorreu com alguns livros precursores, estas também se constituem, ainda hoje, em fontes de consulta e referenciação para os estudos que se dedicam a revisitar o percurso histórico do ensino de PLE no Brasil. Arai (1985); Caldas (1988); Morita (1993); Weiss (1994) e Dell'Isola (1999) são alguns exemplos.

A partir de meados dos anos 80, surgiu uma consciência de Área. Diversas ações foram realizadas para firmar o PLE como um campo de estudo nas universidades e nos centros de língua. Como exemplo, podemos citar: os livros para formação de professores lançados nas décadas de 1990 e 2000 (ALMEIDA FILHO, 1999; CUNHA; SANTOS, 2002); a criação do 
exame de proficiência Celpe-Bras em 1994; e o lançamento de uma série de livros didáticos utilizados no Brasil e no exterior. Desse material se destacam, pela expressão e repercussão no ensino de línguas, as obras: "Falar, ler e escrever" (LIMA; IUNES, 1999); "Bem-Vindo" (PONCE et. al 1999), "Muito Prazer" (FERNANDES et. al 2008) e "Novo Avenida Brasil", (LIMA; IUNES, 2008). Cumpre também dizer que o "Programa de Leitorados" da Coordenação de Aperfeiçoamento Pessoal de Nível Superior (CAPES) vem incentivando pesquisas na área desde 1999.

No início do século 21 , incentivados por um contexto global de trânsitos, conexões e referências materiais e simbólicas, frutos de intensas e complexas movimentações geopolíticas e socioespaciais advindas do fluxo migratório contemporâneo, o Brasil havia se constituído em um dos países anfitriões nos processos de migração, especialmente no Sul Global (BAENINGER et. al, 2018) e as instituições de pesquisa começaram a se movimentar na investigação do que poderíamos chamar, talvez, de um fenômeno social que precisava ser agenciado.

Neste contexto de (re)configurações, vimos a criação do Museu da Língua Portuguesa em 2006 - marco simbólico de grande expressividade no que se refere à afirmação do Português como símbolo da identidade nacional e instrumento de pertencimento social; a ampliação da oferta de PLE no exterior, principalmente na América Latina graças a motivações econômicocomerciais; a instituição de cursos de graduação em Português como Segunda Língua - destaque para o pioneirismo da Universidade de Brasília (UnB) -; e a criação e desenvolvimento de programas e grupos de pesquisa em IES de todo o país, que robustecerem o Português não apenas como uma marca identitária forte para os brasileiros, mas também como uma língua (inter)nacional (SILVA; SANTOS, 2013) - fator que corrobora a sua difusão e amplia as possibilidades de presença e atuação no Brasil no mercado global.

As ações de política exterior e integração, principalmente na América do Sul (e aqui destacamos o papel fundamental do Mercosul nessa (re)formulação geopolítica), contribuíram para que o PLE cooperasse para o fortalecimento político-econômico do país para além das fronteiras nacionais. A criação e institucionalização de iniciativas como a Sociedade Internacional do Português Língua Estrangeira (SIPLE), o Instituto Internacional da Língua Portuguesa (IILP), o Instituto de Investigação e Desenvolvimento em Política Linguística (IPOL), a Universidade Federal da Integração Latino-Americana (UNILA) e a Associação de Universidades do 
Grupo Montevidéu são exemplos de ações que também têm contribuído nesse processo de valorização e difusão do Português pelo mundo afora.

\section{Português Língua de Acolhimento (PLAC)}

Em meio a esse "acontecimento sociológico" (MORO, 2015, p.187) que é como tem sido percebido o cenário migratório contemporâneo - o que é considerado pelo Alto Comissariado das Nações Unidas para Refugiados (ACNUR) como o maior deslocamento humano desde o pós Segunda Guerra (op cit., 2018) -, temos visto as questões inerentes a esse processo demandarem cada vez mais das sociedades. Afinal, como inserir pessoas que foram deslocadas predominantemente à força de seus países e que se encontram em condições de vulnerabilidade, em lugares onde nunca imaginaram e/ou desejaram estar? Como promover condições de pertencimento a essas pessoas, uma vez que elas não têm autonomia linguística para re-existir na sociedade que as "acolheu"? De acordo com Moro (2015):

À dimensão de pertencimento cultural, devemos associar a dinâmica do evento migratório, suas consequências potencialmente traumáticas e também os modos de aculturação secundária a esta migração e as vicissitudes de toda inscrição em uma nova sociedade e em uma nova língua (p.187)

E é justamente nesse quadro de ambivalências e complexidades que nasce a proposta de ensino de Português como Língua de Acolhimento (PLAc). Um cenário de crise, situações-limite, fragilidades, omissões e ausências estatais, mas que também tem sido lugar de (res)significações sobre o ensino de língua na perspectiva do acolhimento, uma vez que a abordagem norteada pela perspectiva crítica e alicerçada na construção de uma consciência cultural dos aprendizes, abarca questões para além do desenvolvimento de habilidades linguístico-discursivas.

Cumpre dizer que não nos referimos a uma proposta de ensino em substituição às práticas anteriores de PLE, mas a uma abordagem teóricometodológica outra, cujas especificidades alcançam questões discriminatórias, psicossociais e outros aspectos extralinguísticos considerados fundamentais para que a assistência das demandas que se impuseram no fomento da acolhida de migrantes indocumentados, 
refugiados, apátridas e portadores de visto humanitário - público predominante do PLAc - seja efetiva.

Segundo o Alto Comissariado das Nações Unidas para Refugiados (ACNUR), a cada minuto, cerca de 20 pessoas são obrigadas a deixar seus países em razão de sobrevivência. Referimo-nos a um quadro em que as estatísticas já superaram a marca de 70 milhões de pessoas deslocadas à força no mundo, entre as quais aproximadamente $40 \%$ são refugiados. Boa parte desses migrantes tem deixado seu país de origem por motivos de guerra, catástrofes naturais, perseguições, crises econômicas, instabilidade política, discriminação, perseguição e/ou "apenas" saem em busca de melhores oportunidades de vida ${ }^{4}$. São migrantes deslocados pelas mais variadas razões, sujeitos que têm atuado como protagonistas de uma nova ordem global pós-moderna, em que a questão linguística está posicionada não apenas como mais uma problemática a ser agenciada, mas como uma das principais implicações no processo de (re)integração dessas pessoas (IPEA, 2015).

O PLAc, tal qual como ele é operacionalizado atualmente no Brasil, tem sido impulsionado por um cariz geoestratégico (PINTO, 2007), iniciado com a institucionalização do Português como Língua Não Materna (PLNM) em Portugal há alguns anos. Inscrito no contexto da pós-modernidade (HALL, 2003), tem participado do processo de negociação identitária dos aprendizes e corroborado os imperativos da globalização (ELHAJJI, 2012) por meio do intercâmbio, principalmente, cultural. A iniciativa tem, ao que nos parece, contribuído para que deslocamentos e rupturas sociodiscursivas que se dão "à medida que áreas diferentes do globo são postas em interconexão umas com as outras, ondas de transformação social atingem virtualmente toda a superfície da terra e a natureza das instituições modernas, características da globalização" (GIDDENS, 1990, p. 6) apontem para estratégias de gestão linguística possíveis no fomento da acolhida em um cenário de crise.

As especificidades do PLAc fazem parte do cenário da internacionalização da Língua Portuguesa (OLIVEIRA, 2013), a saber, a etapa da $3^{\mathrm{a}}$ periodização da geopolítica da língua, "o período instaurado a partir das novas relações de poder e das novas inserções internacionais dos

\footnotetext{
${ }^{4}$ Podemos problematizar até que ponto essa escolha é, de fato, voluntária, uma vez que, se a situação local fosse favorável, eles não precisariam sair de seus países
} 
países de língua portuguesa na economia mundial.” (p. 53). Vale registrar nesse momento, que

(...) o PLAc é uma prática de ensino-aprendizagem crítica, orientada para - mas não restrita a - deslocados forçados, extensiva para outros grupos de imigrantes em condição de minoritarizados ou de vulnerabilidade que desejem aprender a língua majoritária do Brasil. (LOPEZ, 2018, p.20, destaque adicionado)

Em meio às demandas advindas desse cenário e ao (não) posicionamento do Estado frente às urgências sociolinguísticas de migrantes em situação de fragilidade econômico-social, o PLAc assume certa responsabilidade diante do recomeçar dessas pessoas ao agenciar técnica e subjetivamente aspectos da questão migratória com os quais o ensino de língua estrangeira, nos moldes do PLE, não se propõe a fazer.

Segundo Elhajji (2012), o movimento de idas e vindas constroem significados outros e transformam a morfologia social e humana em diferentes níveis, provocando deslocamentos que não são únicos, mas sim "dúbios e que oferecem infinitas possibilidades de hibridizações, cruzamentos subjetivos, afetivos, simbólicos, imaginários e materiais" (p. 8). Então, como administrar os fatores advindos dessas expressões de subjetividade humana? Não estamos afirmando que o ensino de PLAc assista a todas as demandas e anseios da questão migratória com suas novas configurações identitárias. Isso seria, minimamente, ingênuo. Contudo, é fato que ele tem sido a forma/o meio mais acessível que esses migrantes têm disponível para gerir e gerar suas relações com a sociedade da qual agora fazem parte.

A atual Lei de Migração n ${ }^{\circ} 13.445 / 2017$ não contempla políticas linguísticas em seu dispositivo (COSTA; SILVA, 2018) e é diante deste quadro que a atuação do PLAc frente às necessidades primeiras de sujeitos transplantados (AMADO, 2011) é tão importante. Apesar de a questão migratória ser antiga, constituindo-se, inclusive, uma "condição humana" (ELHAJJI, 2012 p.10), só muito recentemente os governos têm se atentado para o fato de que não fazer nada para que o sujeito migrante, de fato, pertença ao novo endereço de domicílio, além de ignorar o aspecto humanitário da questão, abarca uma série de outras implicações com as quais, cedo ou tarde, ele terá que lidar. Não se trata apenas da concessão de 
entrada e permanência no país, mas da garantia dos direitos e de subsídios para o efetivo exercício de cidadania por meio da acolhida no seu sentido mais amplo. E é isso que o PLAc e outras iniciativas populares têm buscado fazer, ao assistir, entre outras demandas, a necessidades de comunicação que hoje se configuram como um dos principais recursos no processo de (re)integração e pertencimento daqueles que passaram a viver no nosso país.

Segundo mapeamento realizado pelo IPEA (2015), com dados do Ministério da Justiça, entre os principais obstáculos para acesso a direitos e serviços, está o idioma. Instituições, sociedade civil e os próprios migrantes são unânimes em afirmar que o acesso à língua e o seu aprendizado é um dos principais fatores que possibilitam a integração social. Vejamos a tabela 1:

Tabela 1. Principais dificuldades enfrentadas pela população imigrante

\begin{tabular}{lcc}
$\begin{array}{c}\text { Segundo as } \\
\text { instituições }\end{array}$ & $\begin{array}{c}\text { Segundo a } \\
\text { sociedade civil }\end{array}$ & $\begin{array}{c}\text { Segundo os } \\
\text { próprios } \\
\text { imigrantes }\end{array}$ \\
\hline
\end{tabular}

\begin{tabular}{lccc}
\hline Saúde & $5,26 \%$ & $2,70 \%$ & Não informado \\
Educação & $1,58 \%$ & $3,80 \%$ & Não informado \\
Moradia & $10,53 \%$ & $9,78 \%$ & Não informado \\
Trabalho & $10,53 \%$ & $13,04 \%$ & $20,63 \%$ \\
Documentação & $14,21 \%$ & $11,96 \%$ & $13,98 \%$ \\
Informação & $9,47 \%$ & $5,43 \%$ & $2,15 \%$ \\
Idioma & $16,84 \%$ & $16,34 \%$ & $21,74 \%$ \\
Discriminação & $4,74 \%$ & $8,73 \%$ & $5,91 \%$ \\
Financeiras & $3,16 \%$ & $1,63 \%$ & $5,91 \%$ \\
Subsistência & $3,16 \%$ & $1,09 \%$ & $5,38 \%$ \\
Acesso a serviços & Não informado & Não informado & $16,24 \%$ \\
Outros & $20,52 \%$ & $25,50 \%$ & $8,06 \%$ \\
\hline
\end{tabular}

Fonte: Ministério da Justiça/ Instituto de Pesquisa Econômica Aplicada (2015). Formato adaptado. ${ }^{5}$

Ainda segundo esse levantamento, além da dificuldade diretamente relacionada ao idioma, o item denominado "Outros" refere-se a barreiras que, em sua maioria, dificultam o processo de (re)integração dos migrantes

5 . Disponível em:

$\langle\underline{\text { https://somosmigrantessite.files.wordpress.com/2017/01/pesquisa-mj- }}$ servic3a7os-e-direitos.pdf $>$ 
e estão indiretamente relacionados à língua. Adaptação, cultura, questões psicológicas, acolhida, vulnerabilidade e entendimento da legislação são alguns dos exemplos mais expressivos. Tudo isso corrobora a abordagem do PLAc, uma vez que ele pauta sua proposta de trabalho para além dos fatores linguísticos, considerando questões socioculturais, psicossociais e discriminatórias em seu projeto de ensino. Enquanto a condição do sujeito migrante em um contexto de precariedade e faltas o reifica, o PLAc, por meio da lingua(gem), pode fortalecê-lo (LOPEZ; DINIZ, 2019) e contribuir no processo de (re)territorialização (DELEUZE; GUATTARI, 2004) que é potencialmente capaz de contribuir para a emancipação social.

Com um ensino que prevê uma abordagem com foco comunicativo voltado para as necessidade (não somente) mais imediatas, o PLAc orienta seu saber-fazer no afã de atender as carências de sujeitos subalternizados (SPIVAK, 2010), muitas vezes identificados exclusivamente por meio de um discurso de falta "essencialista e totalizador (...) que os significa por aquilo que supostamente 'não são', 'não fazem', 'não sabem', 'não conhecem', apagando suas vivências, suas agências, seus saberes e seus conhecimentos." (DINIZ; NEVES, 2018, p. 100-101).

\section{Considerações finais}

Diante de um cenário em que "o deslocamento migratório é concebido como experiência que implica ruptura do contexto exterior do indivíduo, produzindo possíveis efeitos de desorganização do universo de referências simbólicas" (ARANTES; DEUSDARÁ; BRENNER, 2016, p.1201), é imperioso pensar e agir prioritariamente em atendimento às necessidades e anseios humanos, visando à aproximação e à integração entre as sociedades e povos, à diluição de fronteiras (especialmente as simbólicas) e à construção de relações orientadas pela alteridade dos/para com os sujeitos envolvidos. Do contrário, o cenário migratório continuará sendo encarado pelo viés da problemática e da "forma patológica de inclusão" (MARTINS, 1998).

Considerando o contexto sócio-histórico e o cenário geopolítico, concluímos que o PLAc representa uma perspectiva outra, inovadora e significativa no campo do PLE, uma vez que, além de assistir a demandas não atendidas pelo Estado (COSTA; SILVA, 2018), baseia sua metodologia numa cultura de ensino participada, que respeita os processos de re- 
construção identitária dos sujeitos (ANUNCIAÇÃO, 2018) com foco na promoção da cidadania e na consciência e diálogo interculturais.

Mesmo (r)existindo devido ao trabalhado voluntário de professores, pesquisadores ${ }^{6}$ e profissionais de várias áreas - ainda que territorializado nos cursos de Letras - e sofrendo toda a sorte de carências de investimentos, o PLAc posiciona-se como uma das poucas alternativas de acesso ao aprendizado do idioma de maneira gratuita - diferente da maioria dos cursos de PLE que tem como público-alvo, predominantemente, turistas, estudantes e/ou profissionais de grandes empresas com poder aquisitivo para arcar com as despesas do curso.

Conforme a Portaria Interministerial $\mathrm{n}^{\circ} 16$, de 3 de outubro de 2018, Art. $5^{\circ}$, inciso I, letra ' $d$ ' , que dispõe sobre novas formas de obtenção da naturalização no Brasil, indicando o curso de português nas IES como um dos meios para isso, vemos o quanto a necessidade de se investir, promover e institucionalizar as práticas do PLAc fazem-se cada mais imperativas.

Ao promover o imbricamento de fatores linguísticos e extralinguísticos, o PLAc não apenas privilegia aspectos não contemplados pelo PLE, como posiciona-se como uma nova situação socioeducativa nos estudos da Área. Segundo Cursino et. al (2017) a partir da problematização das diferentes identidades em uma perspectiva que possibilita novas formas de se relacionar com o outro, o PLAc atua como instrumento para expandir a voz do sujeito, fortalecendo a agência humana e facilitando o processo de integração em um novo contexto social.

Para (não) concluir, diríamos que a exploração pelo PLAc da força discursivo-ideológica que a lingua(gem) detém pode fornecer ao sujeito, antes fragilizado, subsídios para se adaptar às engrenagens de funcionamento

6 O Grupo de pesquisa "Migrações, Dinâmicas Territoriais e Integração Regional" (UNILA), o "PROACOLHER" (UnB), O "Português Brasileiro para Migração Humanitária" (UFPR), as parcerias da USP com a Missão Paz e o Oásis Solidário, o "Português para estrangeiros em regime especial de permanência" (UFMG), o Grupo de Estudos Migratórios: Acolhimento, Lingua(gens) e Políticas (GEMALP/CEFET-MG) são alguns exemplos de ações que têm sido desenvolvidas com vistas a dar visibilidade à questão migratória por meio do fomento da acolhida linguística.

${ }^{7}$ Conforme publicação no Diário Oficial da União em 4 de outubro de 2018. Disponível em: http://portal.imprensanacional.gov.br/materia/asset_publisher/Kujrw0TZC2Mb/content/id/43885878/do1-2018-10-04-portariainterministerial-n-16-de-3-de-outubro-de-2018-43885761. Acesso em: 30 jan. 2019. 
da sociedade a que agora pertence, contribuindo na transformação de indivíduos minoritarizados (ANUNCIAÇÃO, 2018) em sujeitos de saber e de poder.

\section{Referências}

ACNUR. Dados sobre refúgio. Disponível em: <http://www.acnur.org/portugues/dados-sobre-refugio/>. 2018. Acesso em: 11 fev. 2019.

ALMEIDA FILHO, José. C.P (Org.). O professor de língua estrangeira em formação. Campinas, São Paulo: Pontes, 1999.

ALMEIDA FILHO, José. C.P. Ensino de português língua estrangeira/EPLE: a emergência de uma especialidade no Brasil. In: LOBO, T. et. al. (Orgs). Rosae: linguística histórica, história das línguas e outras histórias [online]. Salvador: EDUFBA, 2012. p. 723-728.

ALMEIDA FILHO, José. C.P. O Português como língua não-materna: concepções e contexto de ensino. Museu da Língua Portuguesa: Estação da Luz, 2005. Disponível em: <http://museudalinguaportuguesa.org.br/wpcontent/uploads/2017/09/ENSINO-COMO-LINGUA-NAO-

MATERNA.pdf>. Acesso em: 20 mai. 2020.

AMADO, Rosane. S. Português como Segunda Língua para comunidades de trabalhadores transplantados. Revista da Sociedade Internacional Português Lingua Estrangeira (SIPLE), v. 2, 2011.

ANUNCIAÇÃO, Renata. F. M. A língua que acolhe pode silenciar?: reflexões sobre o conceito de "Português como Língua de Acolhimento". Revista X, v. 13, n. 1, p.35-56, 2018.

ARAI, N.A. Fluência na aquisição do PLE. 1985. f. Dissertação (Mestrado em Linguística Aplicada) - Faculdade de Filosofia, Comunicação, Letras e Artes, Pontifícia Universidade Católica de São Paulo, São Paulo, 1985. 
ARANTES, Poliana. C. C.; DEUSDARA, Bruno.; BRENNER, Ana. K. Língua e alteridade na acolhida a refugiados: por uma micropolítica da linguagem. Fórum Linguístico (Online), v. 13, p. 1196-1207, 2016. Disponível em: <https://periodicos.ufsc.br/index.php/forum/article/view/19848412.2016v13n2p1196>. Acesso em: 8 fev. 2019.

BAENINGER, Rosana. A.; PERES, Roberta. G. Migração de crise: a imigração haitiana para o Brasil. Revista Brasileira de Estudos da População, v. 34, n. 1, p.119-143, jan./abr. 2017. Disponível em: http://www.scielo.br/scielo.php?script=sci_arttext\&pid=S01023098201700 0100119\&lng=pt\&nrm=is.o.. Acesso em :12 jan. 2019.

BAENINGER, Rosana et. al. (Orgs.). Migrações sul-sul. 2 ed. Campinas, SP: Núcleo de Estudos de População “ElzaBerquó”/Nepo/Unicamp, 2018.

BRASIL. Nova Lei de Migrações $n^{o}$ 13.445/2017. Disponível em: <http://www.planalto.gov.br/ccivil_03/_ato20152018/2017/lei/L13445.htm>. Acesso em: 30 jan. 2019.

CALDAS, V. M. C. A competência comunicativa em livros didáticos de PE: uma avaliação. Dissertação (Mestrado em Lingüística Aplicada) - Faculdade de Filosofia, Comunicação, Letras e Artes, Pontifícia Universidade Católica de São Paulo, São Paulo, 1988.

CALVET, Louis-Jean. As políticas linguísticas. Florianópolis/São Paulo: Ipol/Parábola. 2007.

CLOCHARD, Olivier. Les réfugiés dans le monde entre protection et illégalité. EchoGéo, n.2, p. 1-27, 2007. Disponível em: <https://journals.openedition.org/echogeo/1696>. Acesso em: 07 mar. 2020.

COSTA, Eric. J.; SILVA, Flávia. C. Legislação migratória e Português como Língua de Acolhimento: reflexões sobre políticas linguísticas e lingua(gem). Revista de Divulgação Científica em Língua Portuguesa, Linguística e Literatura, ano 14, v. 2, n.23, p. 598-612, 2018. 
O ensino de Português como Língua de Acolhimento...

COUDRY, Pierre.; FONTÃO, Elizabeth. Fala Brasil. Campinas: Pontes Editores, 1989.

CUNHA, Maria. J. C.; SANTOS, Percília. Tópicos em Português Língua Estrangeira. Brasília: Ed. da UnB, 2002.

CURSINO, Carla. et al. Português Brasileiro para migração humanitária (PBMIH): reflexões linguísticas e pedagógicas para o ensino de PLE em contexto de migração e refúgio. In: RUANO, Bruna Pupatto; SANTOS, Jovania Maria Perin; SALTINI, Lygia Maria Leite (Orgs.). Cursos de português como língua estrangeira no Celin-UFPR: práticas docentes e experiências em sala de aula. Curitiba: Ed. UFPR, 2016. p. 317-136.

DELEUZE, Gilles; GUATTARI, Félix. Mil Platôs: capitalismo e esquizofrenia. V. 3. Rio de Janeiro: Ed. 34, 2004.

DELL'ISOLA, Regina .L.P.. O contexto e a compreensão lexical na leitura em Português Língua Estrangeira. 1999. f. Tese (Doutorado em Estudos Linguísticos) - Faculdade de Letras, Universidade Federal de Minas Gerais, Belo Horizonte, 1999.

DINIZ, Leandro. R. A; NEVES, Amélia. O. Políticas linguísticas de (in)visibilização de estudantes imigrantes e refugiados no ensino básico brasileiro. In: Revista X, v.13, n.1, p. 87-110, 2018.

ELHAJJI, Mohammed. Mapas subjetivos de um mundo em movimento: migrações, mídia étnica e identidades transnacionais. In: MAIA, J; HELAL, C. (Orgs.). Comunicação, arte e cultura na cidade do Rio de Janeiro. Rio de Janeiro: Ed. UERJ, 2012. p. 215-238.

FERNANDES, Gláúcia R. R; FERREIRA, Telma. L.S.B; Ramos, Vera. L. Muito prazer!: fale o Português do Brasil. Editora Disal, 2008.

GIDDENS, Anthony. The consequences of modernity. Cambridge: Polity Press, 1990.

GROSSO, Maria. J. Língua de acolhimento, língua de integração. Horizontes de Linguística Aplicada, v. 9, n. 2, p. 61-77, 2010. 
HALL, Stuart. A identidade cultural na pós-modernidade. DP\&A Editora: Rio de Janeiro, 2003.

INSTITUTO DE PESQUISAS ECONÔMICAS APLICADAS - IPEA. Ministério da Justiça, Secretaria de Assuntos Legislativos. Migrantes, apátridas e refugiados: subsídios para o aperfeiçoamento de acesso a serviços, direitos e políticas públicas no Brasil. Brasília. Série Pensando o Direito, n. 57, 2015.

LIMA, Emma E.; IUNES, Samira A. Falar, ler, escrever português. São Paulo: EPU, 1999.

LIMA, Emma E.; IUNES, Samira A. Novo Avenida Brasil. São Paulo: EPU, 2008.

LIMA, Emma.E. et al. Avenida Brasil. São Paulo: EPU, 1992.

LOPEZ, Ana. Paula A.. A aprendizagem de português por imigrantes deslocados forçados no Brasil: uma obrigação? Revista X, v.13, n.1, p. 9-34, 2018.

LOPEZ, Ana Paula. A.; DINIZ, Leandro. R. A. Iniciativas jurídicas e acadêmicas para o acolhimento no Brasil de deslocados forçados. Revista da Sociedade Internacional Português Língua Estrangeira - Siple v. 9, [s.p.], 2019.

MARTINS, José S. O problema das migrações no limiar do terceiro milênio. In: O fenômeno migratório no limiar do terceiro milênio. Desafios Pastorais. Petrópolis: Editora Vozes, 1998.

MORITA, Marisa K. Diálogo a distância no processo de aquisição da oralidade em LE. Dissertação (Mestrado em Lingusística Aplicada) Instituto de Estudos da Linguagem, Unicamp, São Paulo, 1993.

MORO, Marie. R. Psicoterapia transcultural da migração. Revista Psicologia USP, São Paulo , v. 26, n.2, p.186-192, 2015. 
OLIVEIRA, Antônio. T. R. Migrações internacionais e políticas migratórias no Brasil. Cadernos OBMigra, n. 3, v. 1, s.p, 2015.

OLIVEIRA, Gilvan. M. Um atlântico ampliado: o português nas políticas linguísticas do século XXI. In: LOPES, Luiz P. M (Org.). O português no século XXI. São Paulo: Parábola, 2013.

PEREIRA, Giselda. F. Práticas para o ensino de português como língua de acolhimento em contexto escolar não formal: uma pedagogia intercultural. 2016. 245f. Tese (Doutorado em Letras) - Centro de Comunicação e Letras, Universidade Presbiteriana Mackenzie, São Paulo, 2016. Disponível em: <http://tede.mackenzie.br/jspui/handle/tede/3216>. Acesso em 22 fev. 2019.

PINTO, Alexandre. D. A institucionalização do Português Língua Não Materna em Portugal. Revista Proformar, v. 21, p. 2007. Disponível em: < http://proformar.pt/revista/edicao_21/institucionaliza_portugues.pdf $>$.

Acesso em: 27 fev. 2019.

PONCE, Maria Harumi et al. Bem-Vindo!: A língua portuguesa no mundo da comunicação. São Paulo: SBS, 1999.

RAMALHETE, Raquel. Tudo Bem. Rio de Janeiro: AoLivro Técnico, 1984.

REVUZ, Christine. A língua estrangeira entre o desejo de um outro lugar e o risco do exílio. In: SIGNORINI, I. (Org.). Língua(gem) e identidade. 2. ed. Campinas, SP: Mercado das Letras, 1998. p. 213-230.

SANTOS, Milton. Por uma outra globalização: do pensamento único à consciência universal. Rio de Janeiro/São Paulo: Editora Record, 2001.

SÃO BERNARDO, Mirelle. A. Português como língua de acolhimento: um estudo com imigrantes e pessoas em situação de refúgio no Brasil. 2016. 206 f. Tese (Doutorado em Linguística) - Centro de Educação e Ciências humanas, Universidade Federal de São Carlos, São Carlos, 2016.

SILVA, Kleber. A; SANTOS, Danúsia. T. O português como língua (inter)nacional. Campinas: Pontes Editores, 2013. 
Flávia Campos Silva; Eric Júnior Costa

SPIVAK, Gayatri. Pode o subalterno falar? Belo Horizonte: Editora UFMG, 2010.

TROUCHE, Lygia. M. G. O Marqués de Pombal e a implentação da língua portuguesa no Brasil: reflexões sobre o Diretório 1757. Cadernos de Letras da UFF, Niteroi, n.1, p. 97-110, 2001.

WEISS, Denise. B. Ensino do artigo em cursos de português para japoneses. 1994. f. Dissertação (Mestrado em Lingüística) - Faculdade de Letras, Universidade Federal do Rio de Janeiro, Rio de Janeiro, 1994.

ZOPPI-FONTANA, Mônica. G. O português do Brasil como língua transnacional. Editora RG, Campinas, 2009.

Recebido em: 30/08/2019

Aceito em: 04/05/2020

Title: The teaching of Portuguese as a Host Language (PHL) in the timeline of studies about Portuguese as a Foreign Language (PFL) in Brazil 